\title{
The Long-Term Impact of COVID-19 Pneumonia on the Pulmonary Function of Survivors
}

\author{
Ayad Mohammed Salem (D) \\ Noor Al Khathlan ${ }^{2}$ \\ Abdulelah Fawzi Alharbi ${ }^{3}$ \\ Turki Alghamdi ${ }^{3}$ \\ Saleh AIDuilej ${ }^{3}$ \\ Mohammed Alghamdi ${ }^{3}$ \\ Majed Alfudhaili ${ }^{3}$ \\ Ahmed Alsunni (iD) \\ Talay Yar (D)' \\ Rabia Latif ${ }^{\prime}{ }^{\prime}$ \\ Nazish Rafique (D') \\ Lubna Al Asoom (iD) \\ Hussein Sabit ${ }^{4}$
}

'Department of Physiology, College of Medicine, Imam Abdulrahman Bin Faisal University, Dammam, Saudi Arabia; ${ }^{2}$ Department of respiratory care, College of Applied Medical Sciences, Imam Abdulrahman Bin Faisal University, Dammam, Saudi Arabia; ${ }^{3}$ College of Medicine, Imam Abdulrahman Bin Faisal University, Dammam, Saudi Arabia; ${ }^{4}$ Department of Genetics, Institute for Research and Medical Consultations (IRMC), Imam Abdulrahman Bin Faisal University, Dammam, Saudi Arabia
Correspondence: Ayad Mohammed Salem Department of Physiology, College of Medicine, Imam Abdulrahman Bin Faisal University, PO Box 21 I4, Dammam, 3145I, Saudi Arabia

Email ayadsalem@iau.edu.sa
Background: The sequelae of COVID-19 pneumonia on pulmonary function and airways inflammation are still an area of active research.

Objective: This research aimed to explore the long-term impact of COVID-19 pneumonia on the lung function after three months from recovery.

Methods: Fifty subjects (age 18-60 years) were recruited and classified into two groups: the control group (30 subjects) and the post-COVID-19 pneumonia group (20 patients). Pulmonary function tests, spirometry, body plethysmography [lung volumes and airway resistance $\left(\mathrm{R}_{\mathrm{aw}}\right)$ ], diffusion capacity for carbon monoxide $\left(\mathrm{DL}_{\mathrm{CO}}\right)$, and fractional exhaled nitric oxide (FeNO), were measured after at least 3 months post-recovery.

Results: Significant reduction in total lung capacity (TLC), forced vital capacity (FVC), forced expiratory volume $\left(\mathrm{FEV}_{1}\right), \mathrm{FEV}_{1} / \mathrm{FEV}$, and diffusing capacity for carbon monoxide $\left(\mathrm{DL}_{\mathrm{CO}}\right)$ was observed in post-COVID-19 subjects compared to controls. Restrictive lung impairment was observed in $50 \%$ of post-COVID-19 cases $(n=10)$ compared to $20 \%$ in the control group ( $\mathrm{n}=6, P=0.026)$. In addition, mild diffusion defect was detected in $35 \%$ (n $=7)$ of the post-COVID-19 group compared to $23.3 \%(\mathrm{n}=7)$ in the controls $(P=0.012)$. Conclusion: COVID-19 pneumonia has an impact on the lung functions in terms of restrictive lung impairment and mild diffusion defect after three months from recovery. Therefore, a long-term follow-up of the lung function in post-COVID-19 survivors is recommended.

Keywords: COVID-19, pneumonia, PFT, DL ${ }_{\mathrm{CO}}, \mathrm{FeNO}$

\section{Introduction}

Coronavirus disease 2019 (COVID-19) caused by severe acute respiratory syndrome coronavirus-2 (SARS-CoV-2) is the third and largest coronavirus outbreak with more than 152,907,113 million confirmed cases and 3,208,543 deaths as of 2nd of May 2021. ${ }^{1}$ COVID-19 originated in China in December 2019 with multiple cases presenting as pneumonia spreading through contact with infected individuals. It spread rapidly across China and quickly spilled over to other countries. The World Health Organization (WHO) declared COVID-19 as a pandemic in March $2020 .^{2}$

COVID-19 has an impact on multiple organs such as the heart, ${ }^{3}$ kidneys, ${ }^{4}$ and liver ${ }^{5}$ but the primary system affected has been the respiratory system with most of the clinical manifestations including cough, sputum production, dyspnea, fever, fatigue, and in severe cases acute respiratory distress syndrome (ARDS) and respiratory failure. ${ }^{6-8}$ The route of transmission of SARS-CoV-2 is through the respiratory system, the virus invades type 2 alveolar cells in the lung, it attaches to 
specific angiotensin-converting enzyme 2 (ACE2) receptors, multiplies inside the cells, and elicits inflammatory response with vasodilatation, increased pulmonary capillaries permeability, necrosis of endothelial cells, and in the severe cases this could progress to acute systemic inflammatory responses and cytokine storm. ${ }^{9}$ The virus may enter the circulation and cause systemic multiple organ failure especially in tissues having ACE2 receptors such as the heart and kidneys. ${ }^{10}$ Autopsy findings of the lung tissue revealed inflammatory cell infiltration and fluid accumulation inside the alveoli, destruction of the alveolar wall, lung fibrosis, and formation of micro-thrombi in the pulmonary capillaries. ${ }^{11}$

Long-term follow-up of survivors from previous outbreaks caused by other coronaviruses infection showed impairment in the pulmonary function tests (PFT) that persisted for months to years after recovery. ${ }^{12}$ A metaanalysis included 28 studies about long-term effects of severe acute respiratory syndrome-associated coronavirus (SARS-CoV) and the Middle East respiratory syndrome coronavirus (MERS-CoV) on the lung function found persistent impairment in $\mathrm{DL}_{\mathrm{CO}}, \mathrm{FVC}$, and TLC up to six months after recovery. However, the impairment in $\mathrm{DL}_{\mathrm{CO}}$ persisted even after 6 months. ${ }^{12}$

Only a few studies have investigated the effects of COVID-19 pneumonia on the lung function. A study done on 55 survivors of COVID-19 after 3 months of discharge revealed some abnormalities in the CT scan in 39 patients (70,91\%), compared to 16 patients without any CT abnormalities, a concomitant impairment in PFT was also found in $14(25.45 \%)$ of these patients. ${ }^{13}$ Another follow-up study of 76 survivors of COVID-19 in Wuhan Union Hospital for three months after discharge showed persistent impairment in FEV1, FEV1/FVC ratio, and $\mathrm{DL}_{\mathrm{CO}}$ in about $32.42 \%$ of cases. ${ }^{14}$ Furthermore, a study on 13 COVID-19 patients at the time of discharge and 6 weeks later showed abnormalities in the lung function with a decrease in FVC and FEV1 along with an increase in FEV1/FVC which demonstrates a restrictive pattern. ${ }^{15}$ However, after 6 weeks, all measurements improved except FVC that remained below the lower limit of normality. Recently, two prospective cohort studies were done at 6 weeks, ${ }^{16}$ and 3 months ${ }^{17}$ after discharge exhibited abnormal $\mathrm{DL}_{\mathrm{CO}}$ with a coexistent restrictive and obstructive ventilatory deficit. A systematic review that examined seven studies about the effect of COVID 19 on the PFT concluded that the most important parameter affected amongst the PFTs was the diffusion capacity that was evident in approximately $40 \%$ of the total number of patients. ${ }^{18}$ However, the time of the respiratory assessment reported in these studies range from a few days to 3 months after hospital discharge. There are hardly any studies investigating the effect of COVID-19 on respiratory function longer than 3 months after the recovery. ${ }^{18}$

Thus, this observational study aimed to investigate the impact of COVID-19 pneumonia on pulmonary function measurements after three months from recovery. As a secondary objective, we investigated the correlation of the lung function with the demographic and clinical characteristics of the patients.

\section{Methods}

\section{Participants and Study Design}

This was a cross-sectional case-control study including 50 subjects (18-65 years). Participants were classified into two groups: Control $(\mathrm{n}=30)$, who tested negative for COVID-19, and post -COVID-19 pneumonia survivors $(n=20)$ after three months of recovery. Post-COVID-19 pneumonia patients were identified retrospectively through the medical records of the cases admitted in King Fahad University Hospital (KFHU), Imam Abdulrahman Bin Faisal University during the period from March 2020 to October 2020. The sample size was determined based on previous similar studies investigating the effect of COVID-19 on pulmonary function. The total number of the subjects in those studies ranged from $18^{19,20}$ to $110^{21}$ participants, and all participants were recruited by convenient sampling technique. This study was conducted according to the Declaration of Helsinki and was approved by the Institutional Review Board of Imam Abdulrahman Bin Faisal University (IRB-UGS-2020-01-409). All subjects were informed about the study purpose and written consent was obtained from each participant.

COVID-19 pneumonia cases were included according to the following inclusion criteria: 1) Patients were confirmed positive for SARS-CoV-2 infection according to CDC criteria by real-time polymerase chain reaction (RT-PCR using nasal and pharyngeal swab specimens, ${ }^{22}$ and were diagnosed with pneumonia by clinical and imaging manifestations (chest X-ray and/or CT scan), 2) The time from recovery was more than three months; recovery was defined as being free of fever and respiratory symptoms for at least 3 days followed by 2 negative PCR tests 24 hours apart, or if PCR was not available, resolution of the clinical manifestations for 3 days and at least 10 days have passed since the first symptom appeared. ${ }^{23} \mathrm{We}$ excluded post-COVID cases according to the following 
exclusion criteria: 1) COPD or other respiratory diseases, 2) neurological disease, 3) mental illness, 4) critically ill patients with intubation, 5) smokers, and those who could not perform the PFT measurements correctly. The flow of post COVID-19 pneumonia patients is shown in (Figure 1). The controls were healthy non-smoker volunteers from our university students and employees with no history of asthma, allergy, chronic pulmonary diseases, past COVID-19 infection, and who were tested negative by PCR.

Over the 4-month recruitment period (from November 2020 to February 2021), fifty subjects were enrolled (30 control and 20 post-COVID-19 pneumonia). The data regarding demographics, medical history, co-morbidities, laboratory investigations, and treatment were collected from patients' medical records at KFHU. The subjects then underwent spirometry, body plethysmography [lung volumes and airway resistance (Raw)], diffusion capacity for carbon monoxide $\left(\mathrm{DL}_{\mathrm{CO}}\right)$, and fractional exhaled nitric oxide (FeNO).

\section{Pulmonary Function Test (PFT)}

All PFT measurements were performed at Pulmonary

Function Laboratory- Respiratory Care Department-
College of Applied Medical Sciences, Imam Abdulrahman Bin Faisal University, according to the American Thoracic Society (ATS) and European Respiratory Society (ERS) guidelines $^{24}$ using $\operatorname{Vmax}^{\circledR}$ Encore PFT System (US). Correct performance of PFT measurements was ensured by a qualified pulmonary function technologist.

The following parameters were measured: Forced Vital Capacity (FVC), Forced Expiratory Volume in the First Second $\left(\mathrm{FEV}_{1}\right)$, Forced Expiratory Flows at 25 and $75 \%$ of FVC ( $\left.\mathrm{FEF}_{25 \%-75 \%}\right)$, Peak Expiratory Flow (PEF), FEV 1 /FVC, Total Lung Capacity (TLC), Vital Capacity (VC), Inspiratory Capacity (IC), Expiratory Residual Volume (ERV), airway resistance $\left(\mathrm{R}_{\mathrm{aw}}\right)$, and $\mathrm{DL}_{\mathrm{CO}}$ using singlebreath technique with adjustment for hemoglobin concentration. All PFT measurements were expressed as absolute values and percentage of predicted normal values ( $\%$ predicted), the percentage of predicted normal values were calculated automatically based on age, sex, height, and ethnicity according to Hankinson et al reference equation. ${ }^{25}$ Each subject has done three accepted maneuvers and then the highest values were recorded and used in the subsequent analyses.

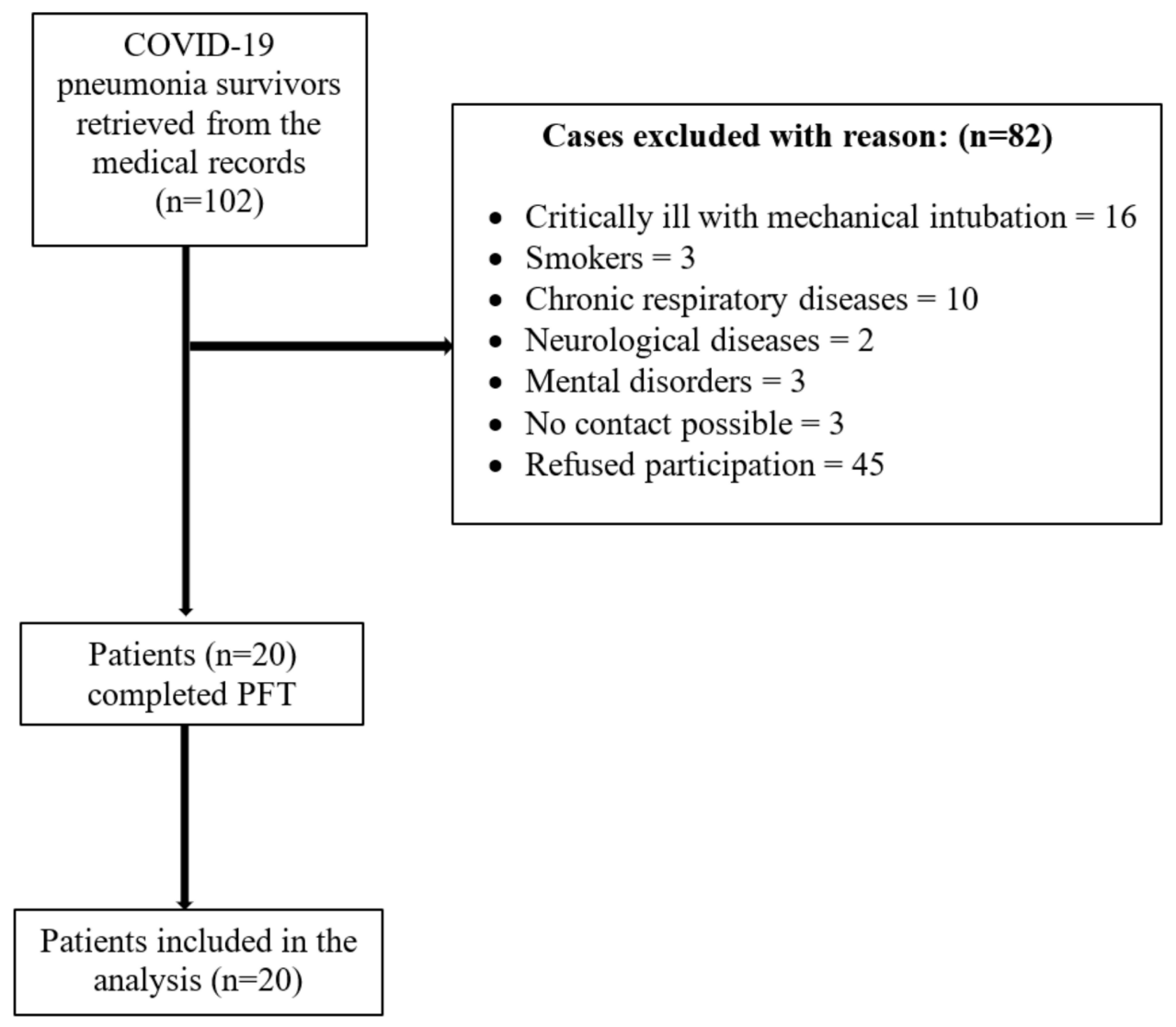

Figure I Flow chart of post COVID-19 patients. 
The criteria for classifying lung function abnormalities were based on ATS Guidelines, ${ }^{26,27}$ as following: Normal: if both $\mathrm{FVC}$ and the $\mathrm{FEV}_{1} / \mathrm{FVC}$ ratio are in the normal range. Obstructive Pattern: if $\mathrm{FEV}_{1} / \mathrm{FVC}$ ratio was $<70 \%$ of the normal predicted value and $\mathrm{FEV}_{1}<80 \%$ of predicted. Restrictive Pattern: if $\mathrm{FEV}_{1} / \mathrm{FVC}$ ratio was $\geq 70 \%$ of the normal predicted value, and the TLC $<80 \%$ of the predicted value. If TLC was not available, a reduction in the $\mathrm{FVC}<80 \%$ of predicted was considered as a restriction pattern. Small airway disease: if $\mathrm{FEF}_{25 \%-75 \%}$ was $<65 \%$ of normal predicted value. Impaired diffusion: Normal DLCO: $>75 \%$ of predicted, Mild diffusion defect: $60 \%$ to $75 \%$ of predicted, Moderate diffusion defect: $40 \%$ to $60 \%$ of predicted, Severe diffusion defect: $<40 \%$ of predicted.

\section{Fractional Exhaled Nitric Oxide (FeNO)}

FeNO is a quantitative noninvasive method of measuring airway inflammation that provides a supportive tool for evaluating airways diseases. FeNO measurement was performed by using FeNO analyzer NIOX VERO (Aerocrine, Sweden). It was done according to the (ATS/ERS) recommendations. ${ }^{28}$ The subjects performed two exhalations at a flow of $50 \mathrm{~mL} / \mathrm{s}$, the mean was used for the analysis. Subjects were instructed to avoid exercise and consumption of nitrate-rich diets at least 2 hours before measurement. ${ }^{28}$

\section{Laboratory Investigations}

The following laboratory investigations were retrieved from the medical records of the post-COVID pneumonia cases at the time of admission: Complete blood count $(\mathrm{CBC})$, arterial blood gases (ABG), clotting profile, and inflammatory markers. Beckman Coulter flow cytometer (USA) was used to measure hematology parameters.

\section{Statistical Analysis}

Continuous variables were described using mean with standard deviation (SD) or median with interquartile range (IQR). Group comparisons were done using unpaired $t$-test or Mann-Whitney test for data that had normal and non-normal distribution, respectively. The Chisquare test was used to compare the categorical variables. Pearson's correlation was used to test any association between variables. Independent predictors for the presence of impaired pulmonary function were investigated using logistic regression analysis. P value $<0.05$ was considered statistically significant. Statistical analyses were performed using SPSS Version 21.0.

\section{Results}

The demographic and clinical characteristics of the participants are presented in (Table 1). Both groups were matched in age, sex, and BMI. The most frequent symptoms at the time of admission were fever, cough, and dyspnea (17 cases, $81 \%$ ), followed by loss of smell and taste (12 cases, $57.1 \%)$. The mean time of assessment after discharge was 166.52 days (102-283 days). At the time of admission there was elevation of the inflammatory markers, ESR $(46.55 \pm 29.90 \mathrm{~mm} / \mathrm{hr})$ and CRP $(8.47 \pm$ $7.61 \mathrm{~mm} / \mathrm{hr}$ ). The initial coagulation profile showed elevated $\mathrm{D}$-dimer $(1.17 \pm 0.91 \mathrm{mcg} / \mathrm{mL})$. The arterial blood gases (ABGs) showed significant reduction in $\mathrm{PaO} 2$ (37.44 $\pm 16.41 \mathrm{mmHg})$ and $\mathrm{SaO} 2(65.31 \pm 26.57 \%)$ upon admission. Other clinical characteristics are shown in (Table 1).

Several spirometry values: FVC, FVC \%PRED, $\mathrm{FEV}_{1}$, PEF and PEF \%PRED showed marked reduction in postCOVID-19 pneumonia group compared to the control $(P<$ 0.01 ) (Table 2). Similarly, a reduction in lung volumes was observed in post-COVID-19 patients including TLC, TLC \%PRED, VC, VC \%PRED and IC $(P<0.05)$. $\mathrm{DL}_{\mathrm{CO}}$ was also reduced in the post-COVID-19 group compared to the control group respectively $(8.33 \pm 1.94$ vs $6.49 \pm 2.28, P=$ 0.004). Other PFT measurements did not show significant differences (Table 2). A significant restrictive lung impairment was observed in 50\% of post-COVID-19 cases ( $\mathrm{n}=$ 10) compared to the control group $(20 \%, \mathrm{n}=6, P=0.026)$. Also, a significant mild diffusion defect was detected in $35 \%(\mathrm{n}=7)$ of the post-COVID-19 group compared to $23.3 \%(\mathrm{n}=7)$ in the controls $(P=0.012)$ (Figure 2).

The female sex was identified as an independent predictor for impaired lung diffusion using multivariable logistic regression $(P=0.024)$. No significant predictor for the restrictive pattern was detected (Table 3 ).

The FVC \%PRED was correlated positively with the use of antiviral therapy during admission $(P=0.049, \mathrm{r}=$ 0.435). No significant correlation was detected with the other variables (Table 4)

\section{Discussion}

COVID-19 pandemic brought a lot of questions regarding long-term sequelae in patients affected with COVID-19 pneumonia. Our study aimed to compare pulmonary function between post-COVID-19 pneumonia survivors after three months from recovery compared to normal 
Table I Demographic and Clinical Characteristic of Participants

\begin{tabular}{|c|c|c|c|c|}
\hline Variable & Reference Values & $\begin{array}{l}\text { Post COVID-19 } \\
(\mathrm{N}=\mathbf{2 0})\end{array}$ & $\begin{array}{l}\text { Control } \\
(\mathrm{N}=30)\end{array}$ & $P$ value \\
\hline Age years (mean + SD) & & $47.05 \pm 11.57$ & $41.93 \pm 11.27$ & 0.126 \\
\hline Gender $n$ (M/F) & & $13 / 7$ & $21 / 9$ & 0.717 \\
\hline BMI kg/m² (mean + SD) & & $28.95 \pm 4.67$ & $29.22 \pm 5.93$ & 0.866 \\
\hline $\begin{array}{l}\text { Care modality } \mathbf{N}(\%) \\
\text { Hospital admission } \\
\text { ICU }\end{array}$ & & $\begin{array}{l}18(90) \\
2(10)\end{array}$ & & \\
\hline $\begin{array}{l}\text { Symptoms at admission } \mathbf{N}(\%) \\
\text { Fever } \\
\text { Cough } \\
\text { Dyspnea } \\
\text { Loss of smell and taste }\end{array}$ & & $\begin{array}{l}17(81) \\
17(8 I) \\
17(8 I) \\
12(57.1)\end{array}$ & & \\
\hline Duration of hospital stay/ days & & $10.71 \pm 6.57$ & & \\
\hline Mean time of assessment after discharge/days Mean (Range) & & $166.52(102-283)$ & & \\
\hline $\begin{array}{l}\text { Laboratory data at admission (mean } \pm \text { SD) } \\
\text { Red blood cells }(\text { Mil/ul) } \\
\text { Hgb concentration }(\mathrm{g} / \mathrm{dL}) \\
\text { White blood cells }(\mathrm{k} / \mathrm{ul}) \\
\text { Neutrophil }(\%) \\
\text { Lymphocyte }(\%) \\
\text { Platelet count }(\mathrm{k} / \mathrm{ul}) \\
\text { ESR }(\mathrm{mm} / \mathrm{hr}) \\
\text { CRP }(\mathrm{mg} / \mathrm{dL})\end{array}$ & $\begin{array}{c}(4.7-6.1) \\
(13.0-18.0) \\
(4.0-11.0) \\
(40-75) \\
(20-45) \\
(140-450) \\
(0-15) \\
(0.10-0.5)\end{array}$ & $\begin{array}{c}4.69 \pm 0.97 \\
12.85 \pm 2.59 \\
11.47 \pm 14.84 \\
65.82 \pm 18.06 \\
21.11 \pm 9.69 \\
240.95 \pm 112.56 \\
46.55 \pm 29.90 \\
8.47 \pm 7.61\end{array}$ & & \\
\hline $\begin{array}{l}\text { Blood coagulation at admission (mean } \pm \text { SD) } \\
\text { PT (sec) } \\
\text { aPTT }(\mathrm{sec}) \\
\text { D-Dimer }(\mathrm{mcg} / \mathrm{mL})\end{array}$ & $\begin{array}{c}(12.9-15.9) \\
(25.6-42.3) \\
(0-0.5)\end{array}$ & $\begin{array}{c}13.24 \pm 0.72 \\
37.58 \pm 4.00 \\
1.17 \pm 0.91\end{array}$ & & \\
\hline $\begin{array}{l}\text { Blood gas analysis at admission (mean } \pm \text { SD) } \\
\mathrm{PaO} 2(\mathrm{mmH}) \\
\mathrm{SaO} 2(\%) \\
\mathrm{PaCO} 2(\mathrm{mmH}) \\
\mathrm{HCO} 3(\mathrm{mmol} / \mathrm{L}) \\
\mathrm{PH}\end{array}$ & $\begin{array}{c}(83-108) \\
(96-99) \\
(35-45) \\
(22-26) \\
(7.35-7.45)\end{array}$ & $\begin{array}{c}37.44 \pm 16.41 \\
65.31 \pm 26.57 \\
38.91 \pm 7.95 \\
25.13 \pm 2.25 \\
7.43 \pm 0.05\end{array}$ & & \\
\hline SaO2\% 3-6 months (mean \pm SD) & & $98.58 \pm 0.90$ & & \\
\hline $\begin{array}{l}\text { Treatment during hospitalization N (\%) } \\
\text { Hydroxychloroquine } \\
\text { Antibiotics } \\
\text { Corticosteroid } \\
\text { Anti-viral } \\
\text { Anti-clotting (Enoxaparin) }\end{array}$ & & $\begin{array}{l}14(70) \\
19(90.5) \\
7(33.3) \\
13(61.9) \\
13(61.9)\end{array}$ & & \\
\hline
\end{tabular}

Note: Data are presented as mean \pm SD, and Number (\%).

Abbreviations: BMI, body mass index; CRP, C-reactive protein; ESR, Erythrocyte sedimentation rate; Hgb, Hemoglobin; SaO2, oxygen saturation; PT, Prothrombin Time; aPTT, Activated partial thromboplastin time; $\mathrm{PaO} 2$, Partial pressure of oxygen; $\mathrm{PaCO}$, partial pressure of carbon dioxide; $\mathrm{HCO}$, Bicarbonate. 
Table 2 Comparison of Pulmonary Function Tests Between the Control Group and Post-COVID-19 Patients After Three Months from Recovery

\begin{tabular}{|c|c|c|c|}
\hline Pulmonary Function Tests & $\begin{array}{l}\text { Control } \\
(\mathrm{N}=30)\end{array}$ & $\begin{array}{c}\text { COVID-19 } \\
(\mathrm{N}=20)\end{array}$ & $P$ value \\
\hline \multicolumn{4}{|l|}{ Spirometry (mean \pm SD) } \\
\hline FVC (Liters) & $4.05 \pm 0.78$ & $3.27 \pm 0.90$ & 0.002 \\
\hline FVC \%PRED (\%) & $91.20 \pm 11.92$ & $83.30 \pm 13.34$ & 0.033 \\
\hline FEVI (Liters) & $3.25 \pm 0.61$ & $2.68 \pm 0.67$ & 0.003 \\
\hline FEVI\%PRED (\%) & $94.30 \pm 12.05$ & $90.30 \pm 12.78$ & 0.267 \\
\hline FEF25-75\% (L/sec) & $3.16 \pm 1.02$ & $3.09 \pm 0.68$ & 0.795 \\
\hline FEF25-75\%PRED (\%) & $85.10 \pm 24.05$ & $95.35 \pm 18.63$ & 0.114 \\
\hline PEF (L/sec) & $7.89 \pm 1.49$ & $6.10 \pm 1.69$ & 0.000 \\
\hline PEF \%PRED (\%) & $99.00 \pm 14.44$ & $85.50 \pm 23.18$ & 0.014 \\
\hline FEVI/FVC (\%) & $80.43 \pm 6.99$ & $82.55 \pm 5.82$ & 0.266 \\
\hline \multicolumn{4}{|l|}{ Lung volumes (mean \pm SD) } \\
\hline TLC (Liters) & $5.89 \pm 1.40$ & $4.81 \pm 1.12$ & 0.008 \\
\hline TLC \%PRED (\%) & $99.92 \pm 19.50$ & $89.11 \pm 12.81$ & 0.041 \\
\hline VC (Liters) & $4.15 \pm 0.82$ & $3.34 \pm 0.91$ & 0.002 \\
\hline VC \%PRED (\%) & $92.76 \pm 12.49$ & $84.95 \pm 13.33$ & 0.042 \\
\hline IC (Liters) & $3.47 \pm 1.28$ & $2.67 \pm 0.59$ & 0.014 \\
\hline IC \%PRED (\%) & $110.76 \pm 24.41$ & $105.05 \pm 20.38$ & 0.403 \\
\hline ERV(Liters) & $0.95 \pm 0.51$ & $0.99 \pm 0.83$ & 0.849 \\
\hline ERV \%PRED (\%) & $65.30 \pm 33.47$ & $61.00 \pm 38.71$ & 0.705 \\
\hline$R_{\text {aw }} \mathrm{cm} \mathrm{H2O/L/sec} \mathrm{median} \mathrm{(IQR)}$ & $0.36(0.22)$ & $0.37(0.22)$ & 0.108 \\
\hline $\mathbf{R}_{\mathrm{aw}} \%$ PRED median (IQR) & $243.50(143)$ & $231.50(96)$ & 0.796 \\
\hline FeNO ppb median (IQR) & $19(15)$ & $16(18)$ & 0.468 \\
\hline \multicolumn{4}{|l|}{ Diffusion capacity (mean \pm SD) } \\
\hline $\mathrm{DL}_{\mathrm{co}}(\mathrm{mmol} / \mathrm{kPa} \cdot \mathrm{min})$ & $8.33 \pm 1.94$ & $6.49 \pm 2.28$ & 0.004 \\
\hline $\mathrm{DL}_{\mathrm{CO}}$ PRED (\%) & $92.10 \pm 15.83$ & $87.95 \pm 18.62$ & 0.411 \\
\hline
\end{tabular}

Notes: Data are presented as mean \pm SD and median (IQR); data in bold indicates significant $P$ value $(<0.05)$.

Abbreviations: FVC, forced vital capacity; FEVI, forced expiratory volume in I s; FEF25-75\%, forced expiratory flow at 25-75\% of FVC; PEF, peak expiratory flow; TLC, total lung capacity; VC, vital capacity; IC, inspiratory capacity; ERV, Expiratory Reserve Volume; $\mathrm{R}_{\mathrm{aw}}$, airway resistance; FeNO, fractional exhaled nitric oxide; $\mathrm{DL}$ co, diffusing capacity of the lung for carbon monoxide.

population. We found a decrease in TLC, TLC \%PRED, $\mathrm{FVC}, \mathrm{FEV}_{1}, \mathrm{FEV}_{1} / \mathrm{FEV}$, and $\mathrm{DL}_{\mathrm{CO}}$. A higher percentage of restrictive lung impairment and mild diffusion defect was detected in the post-COVID-19 group compared to the control group.

Our finding of restrictive lung impairment in about $50 \%$ of post-COVID-19 pneumonia survivors is in line with several previous studies. A recent study done by Fumagalli et al found a significant incidence of a restrictive pattern in $10(76 \%)$ out of 13 patients after 6 weeks from recovery. ${ }^{15}$ Several other studies reported variable prevalence of restrictive pattern in severe COVID-19 infection that ranges from (10.53\%) to $(50 \%) .{ }^{29}$ Recently, a meta-analysis of 7 studies including 380 post-infection COVID-19 cases found $15 \%$ prevalence of restrictive pattern among the reported studies. ${ }^{18}$ These variations in the prevalence of restrictive lung defect among COVID-19 pneumonia survivors could be explained by the differences in the time of assessment which range from close to discharge to three months after discharge. ${ }^{18}$ These studies suggest that patients affected by COVID-19 pneumonia are at increased risk of developing restrictive pulmonary diseases after recovery from the acute illness.

Our study also found mild diffusion defect among 15\% of the post-COVID-19 group. This is consistent with a study conducted by Zhao et al, who reported diffusion impairment in $16 \%$ of post-COVID-19 patients three months after hospital discharge. ${ }^{13}$ In addition, a recent study to evaluate the PFT in post-COVID-19 pneumonia survivors at the time of 


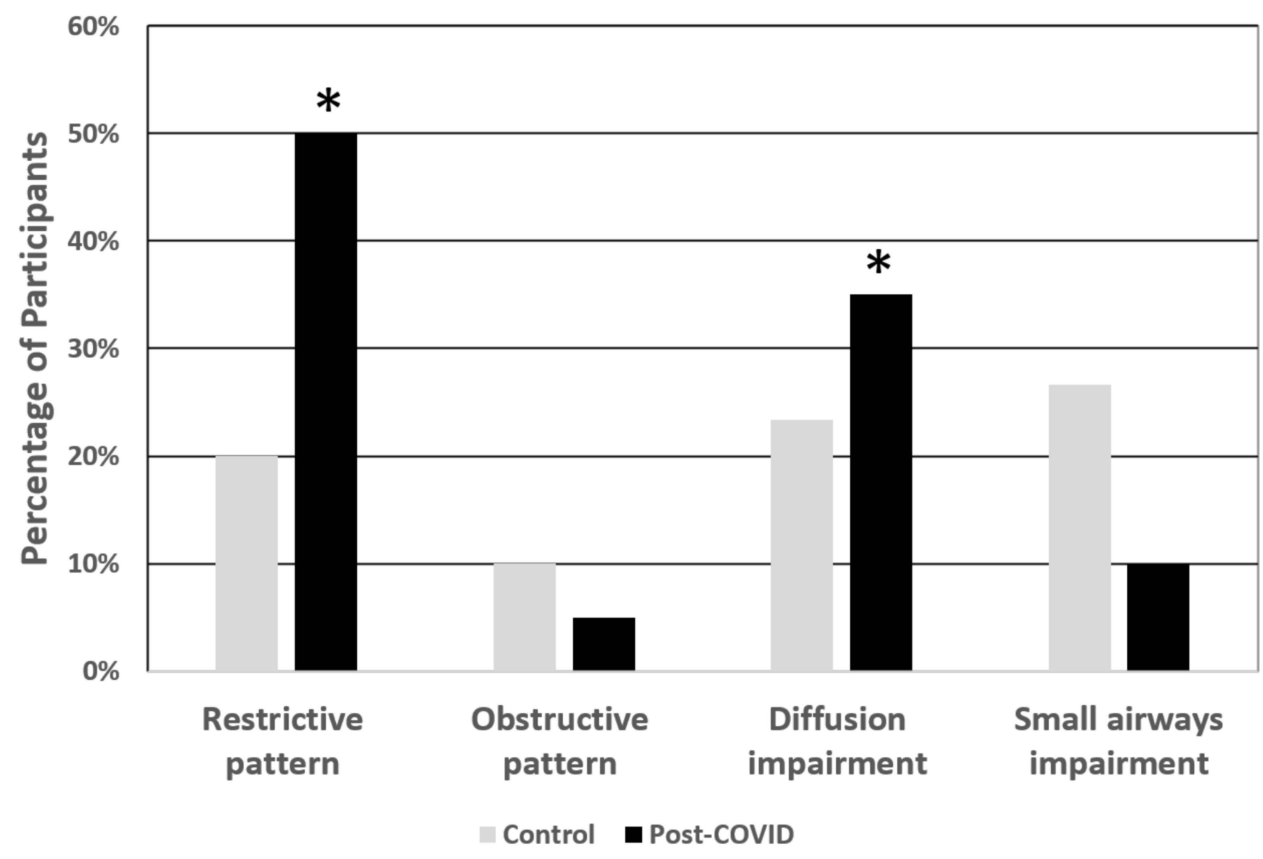

Figure 2 Comparison of PFT impairment patterns between groups. *Significant differences using Chi square test $(p<0.05)$.

discharge found a $47.2 \%$ prevalence of diffusion impairment. ${ }^{21}$ Other studies that assessed PFTs during the first month after infection reported a prevalence of diffusion impairment between $44 \%$ and $56 \% .{ }^{18}$ Again, the wide range of assessment time could explain this difference in the prevalence of diffusion impairment.

The exact mechanism of the injury of the lungs by COVID-19 is still a new subject that is under debate. Studies that included autopsies of COVID-19 patients described an acute lung injury with diffuse alveolar damage associated with fibrotic changes and microthrombi in the pulmonary vasculature. ${ }^{30-32}$ The fibrotic changes in the lung following the acute COVID-19 infection is the most probable mechanism implicated in the restrictive impairment of the lung function, viral lung injury caused by COVID-19 causes recruitment and activation of the fibroblast, and post COVID-19 patients were found to be at higher risk of developing pulmonary fibrosis. ${ }^{33}$ Another possible contributing mechanism to the decline in pulmonary function is the respiratory muscles fatigue, a significant improvement of PFT after 6 weeks of respiratory rehabilitation was observed in post-COVID-19 survivors, ${ }^{34}$ though this rehabilitation did not produce a complete recovery, which may suggest the persistence of lung damage. The underlying mechanism that possibly explains the diffusion impairment in severe cases is the widespread inflammation that caused alveolar destruction and interstitial fibrosis; these changes were evident by autopsies and CT findings. ${ }^{35,36}$

Previous coronaviruses' outbreaks caused by SARS$\mathrm{CoV}$ and MERS-CoV were associated with long-term effects on the lung function with persistent impairment in $\mathrm{DL}_{\mathrm{CO}}, \mathrm{FVC}$, and TLC that lasted up to six months after recovery from the acute illness. ${ }^{12}$ Furthermore, impairment in $\mathrm{DL}_{\mathrm{CO}}$ could persist even after six months. ${ }^{12}$ A study by Ngai et al, in SARS survivors, showed persistent impairment of $\mathrm{DL}_{\mathrm{CO}}$ within two years follow-up period. ${ }^{37}$ Such evidence might be suggestive of a similar outcome for post-COVID-19 pneumonia patients.

Many studies on post-COVID-19 survivors found D-dimer as an important independent predictor of multiorgan damage, ${ }^{13}$ and important prognostic factor related to COVID-19 mortality. ${ }^{38,39}$ In a cohort study in Milan a strong association between $\mathrm{D}$-dimer and $\mathrm{DL}_{\mathrm{CO}}$ was found both during hospitalization and in the follow-up period. ${ }^{40}$ We also observed a similar trend of an elevated D-dimer value at admission for those who showed a restrictive pattern on PFT, though it did not reach a level of significance probably due to small size of our sample.

We found a significant positive correlation between the uses of antiviral therapy during admission with improved FVC. There is a paucity of researches in this field. One animal study on mouse-adapted SARS-CoV-2 found that early use of 
Table 3 Multivariate Logistic Regression Analyses for Impaired Pulmonary Function in the Post-COVID Group After Three Months from Recovery

\begin{tabular}{|c|c|c|c|c|}
\hline \multirow[t]{2}{*}{ Explanatory Variables } & \multicolumn{2}{|c|}{ Restrictive Pattern } & \multicolumn{2}{|c|}{ Impaired Diffusion } \\
\hline & OR (95\% Cl) & $P$ value & OR (95\% CI) & $P$ value \\
\hline Age & $0.99(0.94-1.05)$ & 0.818 & I.0I (0.94-I.07) & 0.852 \\
\hline \multicolumn{5}{|l|}{ Gender } \\
\hline Males & REF & & REF & \\
\hline Females & $3.25(0.92-11.46)$ & 0.067 & $6.00(1.26-28.55)$ & 0.024 \\
\hline BMI & $0.93(0.82-1.06)$ & 0.254 & $0.98(0.85-1.13)$ & 0.762 \\
\hline \multicolumn{5}{|l|}{ Symptoms at admission } \\
\hline Fever & $0.44(0.03-5.88)$ & 0.538 & $1.131+9(0.00-)$ & 0.999 \\
\hline Cough & $2.25(0.17-29.77)$ & 0.538 & $1.09(0.08-14.66)$ & 0.948 \\
\hline Dyspnea & $0.44(0.03-5.88)$ & 0.538 & $0.21(0.02-2.85)$ & 0.240 \\
\hline Loss of smell and taste & $0.43(0.07-2.68)$ & 0.365 & $0.83(0.13-5.40)$ & 0.848 \\
\hline Duration of hospital stay & $0.95(0.8 \mathrm{I}-\mathrm{I} . \mathrm{II})$ & 0.523 & $0.90(0.73-1.11)$ & 0.342 \\
\hline Mean time of assessment after discharge & $0.98(0.96-1.01)$ & 0.141 & $0.99(0.97-1.01)$ & 0.334 \\
\hline \multicolumn{5}{|l|}{ Laboratory data at admission } \\
\hline RBCs (Mil/ul) & $0.45(0.14-1.43)$ & 0.178 & $0.38(0.11-1.25)$ & 0.110 \\
\hline Hgb concentration (g/dL) & $0.78(0.50-1.20)$ & 0.252 & $0.65(0.39-1.1 \mathrm{I})$ & 0.113 \\
\hline WBCs $(k / u l)$ & $1.04(0.93-1.16)$ & 0.484 & $1.05(0.94-1.17)$ & 0.360 \\
\hline Neutrophil (\%) & $1.02(0.96-1.09)$ & 0.472 & $1.02(0.95-1.10)$ & 0.564 \\
\hline Lymphocyte (\%) & $1.00(0.91-1.10)$ & 0.976 & $1.01(0.91-1.12)$ & 0.901 \\
\hline Platelet count (k/ul) & $1.01(1.00-1.01)$ & 0.306 & $1.00(0.99-1.01)$ & 0.533 \\
\hline $\mathrm{ESR}(\mathrm{mm} / \mathrm{hr})$ & $1.01(0.98-1.05)$ & 0.393 & $1.00(0.97-1.03)$ & 0.894 \\
\hline CRP $(\mathrm{mg} / \mathrm{dL})$ & $0.95(0.84-1.08)$ & 0.442 & $0.93(0.79-1.08)$ & 0.329 \\
\hline \multicolumn{5}{|l|}{ Blood coagulation at admission } \\
\hline PT (sec) & $3.08(0.54-17.53)$ & 0.205 & $2.48(0.45-13.66)$ & 0.297 \\
\hline aPTT (sec) & $0.91(0.68-1.21)$ & 0.503 & $1.04(0.78-1.37)$ & 0.812 \\
\hline D-Dimer (mcg/mL) & $2.78(0.68-11.30)$ & 0.153 & $2.29(0.68-7.70)$ & 0.179 \\
\hline \multicolumn{5}{|l|}{ Blood gas analysis at admission } \\
\hline $\mathrm{PaO} 2(\mathrm{mmHg})$ & $1.01(0.94-1.08)$ & 0.769 & $1.02(0.95-1.09)$ & 0.605 \\
\hline $\mathrm{SaO} 2(\%)$ & $1.00(0.96-1.04)$ & 0.945 & I.0I (0.97-I.05) & 0.713 \\
\hline $\mathrm{PaCO} 2(\mathrm{mmHg})$ & $1.04(0.91-1.19)$ & 0.599 & $0.97(0.85-1.12)$ & 0.697 \\
\hline $\mathrm{HCO} 3$ (mmol/L) & $1.56(0.86-2.82)$ & 0.145 & $1.33(0.79-2.26)$ & 0.288 \\
\hline \multicolumn{5}{|l|}{ Treatment during hospitalization } \\
\hline Hydroxychloroquine & $1.00(0.15-6.77)$ & 1.000 & I.II (0.15-8.37) & 0.919 \\
\hline Corticosteroid & $1.56(0.24-9.91)$ & 0.640 & $4.44(0.62-32.07)$ & 0.139 \\
\hline Anti-viral & $0.25(0.03-1.82)$ & 0.171 & $0.59(0.09-3.98)$ & 0.390 \\
\hline Anti-clotting (Enoxaparin) & $0.17(0.02-1.23)$ & 0.079 & $0.83(0.13-5.40)$ & 0.848 \\
\hline
\end{tabular}

Note: Data in bold indicates significant $P$ value $(<0.05)$.

Abbreviations: OR, odds ratio; $\mathrm{Cl}$, confidence interval; BMI, body mass index; CRP, C-reactive protein; ESR, Erythrocyte sedimentation rate; Hgb, Hemoglobin; SaO2, oxygen saturation; PT, Prothrombin Time; aPTT, Activated partial thromboplastin time; PaO2, Partial pressure of oxygen; PaCO2, partial pressure of carbon dioxide; HCO3, Bicarbonate.

antiviral therapy improved the outcome with reduction in viral load and acute lung injury, and better pulmonary function. ${ }^{41}$ We did not find any correlation between corticosteroids and impaired $\mathrm{DL}_{\mathrm{CO}}$, which is consistent with a study that showed no correlation between corticosteroids and $\mathrm{DL}_{\mathrm{CO}}$ among 55 post COVID-19 patients. $^{13}$

Most of the previous studies on the impact of COVID19 on PFT have a limitation of absence of PFT data before 
Table 4 Correlation of Some PFT Measurements with Different Demographic and Clinical Characteristics

\begin{tabular}{|c|c|c|c|c|c|c|c|c|c|c|}
\hline \multicolumn{2}{|l|}{ Variables } & \multirow{2}{*}{$\begin{array}{l}\text { FeNO } \\
0.279\end{array}$} & \multirow{2}{*}{$\begin{array}{l}\text { HT } \\
0.295\end{array}$} & \multirow{2}{*}{$\frac{\text { WBCs Count }}{-0.151}$} & \multirow{2}{*}{$\begin{array}{c}\text { Platelet Count } \\
-0.008\end{array}$} & \multirow{2}{*}{$\begin{array}{l}\text { ESR } \\
0.049\end{array}$} & \multirow{2}{*}{$\begin{array}{l}\text { CRP } \\
0.337\end{array}$} & \multirow{2}{*}{$\begin{array}{l}\text { D-Dimer } \\
-0.025\end{array}$} & \multirow{2}{*}{$\begin{array}{l}\text { Anti-Viral Therapy } \\
0.218\end{array}$} & \multirow{2}{*}{$\begin{array}{l}\text { Steroid } \\
-0.018\end{array}$} \\
\hline TLC \%PRED & $r$ & & & & & & & & & \\
\hline & $\mathrm{P}$ & 0.055 & 0.194 & 0.515 & 0.973 & 0.837 & 0.146 & 0.921 & 0.343 & 0.937 \\
\hline \multirow[t]{2}{*}{ FVC \%PRED } & $r$ & 0.096 & 0.083 & -0.247 & -0.125 & 0.030 & 0.136 & -0.179 & 0.435 & 0.109 \\
\hline & $\mathrm{P}$ & 0.498 & 0.720 & 0.280 & 0.589 & 0.899 & 0.567 & 0.478 & 0.049 & 0.638 \\
\hline \multirow[t]{2}{*}{ DL $_{\text {CO }} \%$ PRED } & $r$ & 0.108 & 0.168 & -0.097 & -0.097 & 0.009 & 0.435 & -0.410 & -0.014 & -0.178 \\
\hline & $\mathrm{P}$ & 0.468 & 0.492 & 0.692 & 0.692 & 0.972 & 0.071 & 0.115 & 0.954 & 0.465 \\
\hline
\end{tabular}

Note: Data in bold indicates significant correlation $(p<0.05)$.

Abbreviations: $r$, Pearson's correlation coefficient; FVC, forced vital capacity; TLC, total lung capacity; DLco, diffusing capacity of the lung for carbon monoxide; CRP, C-reactive protein; ESR, Erythrocyte sedimentation rate; FeNO, fractional exhaled nitric oxide; HT, Hospitalization time; \%PRED, percentage of predicted normal value.

or during the COVID-19 infection to compare with; we tried to overcome this limitation by adding a well-matched control group in our study design. However, the small sample size due to low compliance of the participants because of the current situation of COVID-19 pandemic was a major limitation of the present study.

\section{Conclusion}

COVID-19 pneumonia has an impact on lung function in terms of restrictive lung impairment and mild diffusion defect. Future research should focus on long-term impact of COVID-19 on lung function as well as other body systems. We recommend a follow-up program for all post COVID-19 pneumonia patients for early detection of any complications in the lung function, and to find the appropriate way for rehabilitation and treatment.

\section{Acknowledgment}

The authors would like to acknowledge Mr. Omar Al Omar and Mr. Fahad Al Mutairi (Department of respiratory care - College of applied medical sciences- Imam Abdulrahman Bin Faisal University) for their assistance in PFT procedures.

\section{Disclosure}

The authors report no conflicts of interest in this work.

\section{References}

1. Zhu N, Zhang D, Wang W, et al. A novel coronavirus from patients with pneumonia in China, 2019. N Engl J Med. 2020;382(8):727-733. doi:10.1056/NEJMoa2001017

2. World Health Organization Press Conference. The World Health Organization (WHO) has officially named the disease caused by the novel coronavirus as COVID-19. 2020.

3. Asokan I, Rabadia SV, Yang EH. The COVID-19 pandemic and its impact on the cardio-oncology population. Curr Oncol Rep. 2020;22 (6):020-00945.
4. Pei G, Zhang Z, Peng J, et al. Renal involvement and early prognosis in patients with COVID-19 pneumonia. J Am Soc Nephrol. 2020;31 (6):1157-1165. doi:10.1681/ASN.2020030276

5. Sahu T, Mehta A, Ratre YK, et al. Current understanding of the impact of COVID-19 on gastrointestinal disease: challenges and openings. World J Gastroenterol. 2021;27(6):449-469. doi:10.3748/ wjg.v27.i6.449

6. Jin Y, Yang H, Ji W, et al. Virology, epidemiology, pathogenesis, and control of COVID-19. Viruses. 2020;12(4):372. doi:10.3390/ v12040372

7. Shi H, Han X, Jiang N, et al. Radiological findings from 81 patients with COVID-19 pneumonia in Wuhan, China: a descriptive study. Lancet Infect Dis. 2020;20(4):425-434. doi:10.1016/S1473-3099(20) 30086-4

8. Johnson KD, Harris C, Cain JK, Hummer C, Goyal H, Perisetti A. Pulmonary and extra-pulmonary clinical manifestations of COVID-19. Front Med. 2020;7:526. doi:10.3389/fmed.2020.00526

9. Verdecchia P, Cavallini C, Spanevello A, Angeli F. COVID-19: ACE2centric infective disease? Hypertension. 2020;76(2):294-299. doi:10.1161/HYPERTENSIONAHA.120.15353

10. Zhu H, Rhee JW, Cheng $\mathrm{P}$, et al. Cardiovascular complications in patients with COVID-19: consequences of viral toxicities and host immune response. Curr Cardiol Rep. 2020;22(5):020-01292.

11. Chen W, Pan JY. Anatomical and pathological observation and analysis of SARS and COVID-19: microthrombosis is the main cause of death. Biol Proced Online. 2021;23(1):021-00142. doi:10.1186/ s12575-021-00142-y

12. Ahmed H, Patel K, Greenwood DC, et al. Long-term clinical outcomes in survivors of severe acute respiratory syndrome and Middle East respiratory syndrome coronavirus outbreaks after hospitalisation or ICU admission: a systematic review and meta-analysis. J Rehabil Med. 2020;52(5):16501977-16502694.

13. Zhao YM, Shang YM, Song WB, et al. Follow-up study of the pulmonary function and related physiological characteristics of COVID-19 survivors three months after recovery. EClinicalMedicine. 2020;25:100463. doi:10.1016/j.eclinm.2020.100463

14. Liang L, Yang B, Jiang N, et al. Three-month follow-up study of survivors of coronavirus disease 2019 after discharge. J Korean Med Sci. 2020;35:47. doi:10.3346/jkms.2020.35.e418

15. Fumagalli A, Misuraca C, Bianchi A, et al. Pulmonary function in patients surviving to COVID-19 pneumonia. Infection. 2021;49 (1):153-157. doi:10.1007/s15010-020-01474-9

16. Talman S, Boonman-de Winter L, de Mol M, et al. Pulmonary function and health-related quality of life after COVID-19 pneumonia. Respir Med. 2021;176(106272):30. doi:10.1016/j. rmed.2020.106272

17. Shah AS, Wong AW, Hague CJ, et al. A prospective study of 12-week respiratory outcomes in COVID-19-related hospitalisations. Thorax. 2021;76(4):402-404. doi:10.1136/thoraxjnl-2020-216308 
18. Torres-Castro R, Vasconcello-Castillo L, Alsina-Restoy X, et al. Respiratory function in patients post-infection by COVID-19: a systematic review and meta-analysis. Pulmonology. 2020;25 (20):30245.

19. You J, Zhang L. Anormal pulmonary function and residual CT abnormalities in rehabilitating COVID-19 patients after discharge. $J$ Infect. 2020;81(2):e150-e152. doi:10.1016/j.jinf.2020.06.003

20. Li X, Wang C, Kou S, Luo P, Zhao M, Yu K. Lung ventilation function characteristics of survivors from severe COVID-19: a prospective study. Critical Care. 2020;24(1):300. doi:10.1186/ s13054-020-02992-6

21. Mo X, Jian W, Su Z, et al. Abnormal pulmonary function in COVID-19 patients at time of hospital discharge. Eur Respir J. 2020;55(6):2001217. doi:10.1183/13993003.01217-2020

22. Hanson KE, Caliendo AM, Arias CA, et al. The Infectious Diseases Society of America guidelines on the diagnosis of COVID-19: molecular diagnostic testing. Clin Infect Dis. 2021;22(10).

23. Bhimraj A, Morgan RL, Shumaker AH, et al. Infectious Diseases Society of America guidelines on the treatment and management of patients with COVID-19. Clin Infect Dis. 2020;27(10).

24. Graham BL, Steenbruggen I, Miller MR, et al. Standardization of spirometry 2019 update. An official American Thoracic Society and European Respiratory Society technical statement. Am J Respir Crit Care Med. 2019;200(8):e70-e88. doi:10.1164/rccm.201908-1590ST

25. Hankinson JL, Odencrantz JR, Fedan KB. Spirometric reference values from a sample of the general U.S. population. Am J Respir Crit Care Med. 1999;159(1):179-187. doi:10.1164/ ajrccm.159.1.9712108

26. Pellegrino R, Viegi G, Brusasco V, et al. Interpretative strategies for lung function tests. Eur Respir J. 2005;26(5):948-968. doi:10.1183/ 09031936.05.00035205

27. Graham BL, Brusasco V, Burgos F, et al. 2017 ERS/ATS standards for single-breath carbon monoxide uptake in the lung. Eur Respir J. 2017;49(1):1600016. doi:10.1183/13993003.00016-2016

28. Dweik RA, Boggs PB, Erzurum SC, et al. An official ATS clinical practice guideline: interpretation of exhaled nitric oxide levels (FENO) for clinical applications. Am J Respir Crit Care Med. 2011;184(5):602-615. doi:10.1164/rccm.9120-11ST

29. Frija-Masson J, Debray M-P, Gilbert M, et al. Functional characteristics of patients with SARS-CoV-2 pneumonia at 30 days post-infection. Eur Respir J. 2020;56(2):2001754. doi:10.1183/ 13993003.01754-2020

30. Damiani S, Fiorentino M, De Palma A, et al. Pathological post-mortem findings in lungs infected with SARS-CoV-2. J Pathol. 2021;253(1):31-40. doi:10.1002/path.5549
31. Barton LM, Duval EJ, Stroberg E, Ghosh S, Mukhopadhyay S. COVID-19 autopsies, Oklahoma, USA. Am J Clin Pathol. 2020;153 (6):725-733. doi:10.1093/ajcp/aqaa062

32. Haft JW, Atluri P, Ailawadi G, et al. Adult cardiac surgery during the COVID-19 pandemic: a tiered patient triage guidance statement. J Thorac Cardiovasc Surg. 2020;160(2):452-455. doi:10.1016/j. jtcvs.2020.04.011

33. McDonald LT. Healing after COVID-19: are survivors at risk for pulmonary fibrosis? Am J Physiol Lung Cell Mol Physiol. 2021;320 (2):L257-L65. doi:10.1152/ajplung.00238.2020

34. Liu K, Zhang W, Yang Y, Zhang J, Li Y, Chen Y. Respiratory rehabilitation in elderly patients with COVID-19: a randomized controlled study. Complement Ther Clin Pract. 2020;39(101166):1. doi:10.1016/j.ctcp.2020.101166

35. Yao XH, Li TY, He ZC, et al. [A pathological report of three COVID-19 cases by minimal invasive autopsies]. Zhonghua Bing $\mathrm{Li}$ Xue Za Zhi. 2020;49(5):411-417. [Chinese]. doi:10.3760/cma.j. cn112151-20200312-00193

36. Bao C, Liu X, Zhang H, Li Y, Liu J. Coronavirus disease 2019 (COVID-19) CT findings: a systematic review and meta-analysis. J Am Coll Radiol. 2020;17(6):701-709. doi:10.1016/j. jacr.2020.03.006

37. Ngai JC, Ko FW, Ng SS, To KW, Tong M, Hui DS. The long-term impact of severe acute respiratory syndrome on pulmonary function, exercise capacity and health status. Respirology. 2010;15(3):543-550. doi:10.1111/j.1440-1843.2010.01720.x

38. Zhou F, Yu T, Du R, et al. Clinical course and risk factors for mortality of adult inpatients with COVID-19 in Wuhan, China: a retrospective cohort study. Lancet. 2020;395(10229):1054-1062. doi:10.1016/S0140-6736(20)30566-3

39. Zhang L, Yan X, Fan Q, et al. D-dimer levels on admission to predict in-hospital mortality in patients with Covid-19. J Thromb Haemost. 2020;18(6):1324-1329. doi:10.1111/jth.14859

40. Santus P, Flor N, Saad M, et al. Trends over time of lung function and radiological abnormalities in COVID-19 pneumonia: a prospective, observational, cohort study. J Clin Med. 2021;10(5):1021. doi: $10.3390 / \mathrm{jcm} 10051021$

41. Martinez DR, Schaefer A, Leist SR, et al. Early therapy with remdesivir and antibody combinations improves COVID-19 disease in mice. bioRxiv. 2021. doi:10.1101/2021.01.27.428478
International Journal of General Medicine

\section{Publish your work in this journal}

The International Journal of General Medicine is an international, peer-reviewed open-access journal that focuses on general and internal medicine, pathogenesis, epidemiology, diagnosis, monitoring and treatment protocols. The journal is characterized by the rapid reporting of reviews, original research and clinical studies across all disease areas. The manuscript management system is completely online and includes a very quick and fair peer-review system, which is all easy to use. Visit http://www.dovepress.com testimonials.php to read real quotes from published authors. 